\title{
Mesenchymal Stem Cells can be a Conduit for the Delivery of Therapeutic MicroRNA
}

\section{Pranela Rameshwar*}

UMDNJ-New Jersey Medical School, 185 South Orange Avenue, MSB E-585, Newark, NJ 07103, USA

The advent of discovering the family of small RNAs and their linked to diseases have resulted in methods to apply RNA therapeutics to patients. The delivery of RNAi can occur by short interference RNA (siRNA), short hairpin RNA (shRNA), bifunctional short hairpin RNA and miRNA. The RNAi can suppress translation or degrade mRNA, resulting in the suppression of gene expression through posttranscriptional intervention. A major confound to deliver RNAi is to target the treatment to the desired tissue. This should be done with a delivery system that is stable, non-toxic, refractory to the immune system and equally important, to improve the efficacy of targeted delivery.

Despite the obstacles involved in targeted delivery of RNAi, the research continues to be active, with the goal of developing and identifying methods to treat different disorders. There are clinical trials for macular degeneration, cancer, viral infection and other disorders [1]. There were several trials with RNAi. Unfortunately, relatively few remained in the clinic. This editorial discusses the mesenchymal stem cells (MSCs) as a method to deliver RNAi [2].

There are major efforts to modify current molecules to achieve the ideal goals of delivering RNAi [3]. This includes the effort by biopharmaceuticals to develop new technologies for RNAi treatment [1]. However, the efforts in improving the method of delivering RNAi could be studied in conjunction with MSCs. These stem cells are stable, can be delivered across allogeneic barriers, are easy to acquire from human such as bone marrow aspirates and adipose tissue, can be easily expanded and have reduced ethical concerns [4].

Aptamers have been identified for targeted delivery of RNAi [5]. Although these are synthetic single stranded nucleic acid, the molecules can be arranged into various shapes for specific binding for interaction similar to the method used by antibodies [6]. The aptamers were adapted from those found endogenously from misfolded proteins. Despite the potential application for aptamers, their use in RNAi delivery requires intensive investigation. Nonetheless, this category of transfer molecules could bypass the sought after specificity by using MSCs for delivery.

MSCs express receptors for chemokines and can migrate to the site of inflammation [7]. The MSCs can be 'loaded' with the RNAi, which could be released at the site to inflammation. If the MSCs can form gap junction with the receiving cells, the RNAi could be passed between cells [8]. On the other hand, the RNAi could be transferred through micro vesicles and/or exosomes [9]. Extracellular miRNA can be associated with Ago2 proteins into vesicles for secretions through the forms of exosomes and micro vesicles.

The problem is what will become of the MSCs after their delivery of RNAi. There are clinical trials with MSCs and thus far, there are no reports of untoward effects. Nonetheless, this editorial asks for careful experimental studies to apply MSCs to safely deliver RNAi. The liver could be a test organ to target RNA since the liver is the site of clearance. Translational scientists have taken advantage of the liver and have developed chemical molecules to prevent the replication of hepatitis
B virus. This was achieved with RNAi to prevent the translation of viral proteins, through chemical delivery or adenovirus $[10,11]$. It is expected that these method could progress to those that are relatively less toxic [12]. If the MSCs are safe for the delivery to liver, there could be progress to other organ.

There are clinical and experimental trials to use MSCs for drug delivery to cancer [13]. Similar to inflammatory sites, MSCs can also migrate to tumors. Cancer biologists have developed methods to eliminate the MSCs after drug delivery $[13,14]$. Perhaps similar methods can be used for RNAi therapeutics. The use of MSCs in RNAi therapeutics could be promising, but would require the extrapolation of the vast information on the biology of MSCs as well as their attraction to the site of cancer and tissue damage [14]. The method was applied by loading MSCs with miRNA-containing exosomes for glioblastoma [15]. To reiterate, another method could be the exploration of intercellular communication between MSCs and cancer through gap junction for the exchange of miRNA [8]. At least for cancer, the exploration of intercellular communication might benefit the elimination of the cancer cells such as cancer stem cells that are difficult to target [16].

\section{Acknowledgement}

This work was supported by the Department of Defense and F.M. Kirby Foundation.

\section{References}

1. Kubowicz P, Zelaszczyk D, Pekala E (2013) RNAi in Clinical Studies. Curr Med Chem.

2. Yeo RWY, Lai RC, Zhang B, Tan SS, Yin Y, et al. (2013) Mesenchymal stem cell: An efficient mass producer of exosomes for drug delivery. Adv Drug Deliv Rev 65: 336-341.

3. Kenski DM, Butora G, Willingham AT, Cooper AJ, Fu W, et al. (2012) siRNAoptimized Modifications for Enhanced In Vivo Activity. Mol Ther Nucleic Acids 1: e5.

4. Greco SJ, Rameshwar P (2012) Mesenchymal stem cells in drug/gene delivery: implications for cell therapy. Ther Deliv 3: 997-1004.

5. Zhou J, Bobbin M, Burnett JC, Rossi JJ (2012) Current progress of RNA aptamer-based therapeutics. Frontiers in Genetics 3: 234.

6. Chang YM, Donovan MJ, Tan W (2013) Using aptamers for cancer biomarker discovery. J Nucleic Acids 2013: 817350.

7. Liu H, Liu S, Li Y, Wang X, Xue W, et al. (2012) The Role of SDF-1CXCR4/CXCR7 Axis in the Therapeutic Effects of Hypoxia-Preconditioned

*Corresponding author: Pranela Rameshwar, PhD, UMDNJ-New Jersey Medical School, 185 South Orange Avenue, MSB E-585, Newark, NJ 07103, USA, Tel: (973) 972-0625; Fax: (973) 972-8854; E-mail: rameshwa@umdnj.edu

Received March 28, 2013; Accepted March 30, 2013; Published April 01, 2013

Citation: Rameshwar P (2013) Mesenchymal Stem Cells can be a Conduit for the Delivery of Therapeutic MicroRNA. J Stem Cell Res Ther 3: e112. doi:10.4172/2157-7633.1000e112

Copyright: ( 2013 Rameshwar P. This is an open-access article distributed under the terms of the Creative Commons Attribution License, which permits unrestricted use, distribution, and reproduction in any medium, provided the original author and source are credited. 
Citation: Rameshwar P (2013) Mesenchymal Stem Cells can be a Conduit for the Delivery of Therapeutic MicroRNA. J Stem Cell Res Ther 3: e112. doi:10.4172/2157-7633.1000e112

Mesenchymal Stem Cells for Renal Ischemia/Reperfusion Injury. PLoS One 7: e34608.

8. Lim PK, Bliss SA, Patel SA, Taborga M, Dave MA, et al. (2011) Gap JunctionMediated Import of MicroRNA from Bone Marrow Stromal Cells Can Elicit Cell Cycle Quiescence in Breast Cancer Cells. Cancer Research 71: 1550-1560.

9. Bruno S, Collino F, Deregibus MC, Grange C, Tetta C, et al. (2013) Microvesicles derived from human bone marrow mesenchymal stem cells inhibit tumor growth. Stem Cells Dev 22: 758-771.

10. Wooddell Cl, Rozema DB, Hossbach M, John M, Hamilton HL, et al. (2013) Hepatocyte-targeted RNAi Therapeutics for the Treatment of Chronic Hepatitis $B$ Virus Infection. Mol Ther.

11. Yang X, Marcucci K, Anguela X, Couto LB (2013) Preclinical Evaluation of An Anti-HCV miRNA Cluster for Treatment of HCV Infection. Mol Ther 21: 588601.
12. Poordad F, Lawitz E, Kowdley KV, Cohen DE, Podsadecki T, et al. (2013) Exploratory Study of Oral Combination Antiviral Therapy for Hepatitis C. N Engl J Med 368: 45-53.

13. Shah K (2012) Mesenchymal stem cells engineered for cancer therapy. Adv Drug Deliv Rev 64: 739-748.

14. Yang X, Hou J, Han Z, Wang Y, Hao C, et al. (2013) One cell, multiple roles: contribution of mesenchymal stem cells to tumor development in tumor microenvironment. Cell Biosci 3: 5.

15. Katakowski M, Buller B, Zheng X, Lu Y, Rogers T, et al. (2013) Exosomes from marrow stromal cells expressing miR-146b inhibit glioma growth. Cancer Lett.

16. Patel SA, Ramkissoon SH, Bryan M, Pliner LF, Dontu G, et al. (2012) Delineation of breast cancer cell hierarchy identifies the subset responsible for dormancy. SciRep 2: 906. 